\title{
Liver fluke in Irish sheep: prevalence and associations with management practices and co-infection with rumen fluke
}

\author{
Maria Pia Munita ${ }^{1,2^{*}} \mathbb{0}$, Rosemary Rea ${ }^{2}$, Ana Maria Martinez-lbeas ${ }^{1}$, Noel Byrne', Guy McGrath³, \\ Luis Enrique Munita-Corbalan ${ }^{4}$, Mary Sekiya ${ }^{5}$, Grace Mulcahy ${ }^{5}$ and Ríona G. Sayers ${ }^{1}$
}

\begin{abstract}
Background: The present study aimed to identify the national prevalence of Fasciola hepatica in Irish sheep and to conduct a risk analysis assessment based on management and treatment practices in participating flocks. Also, co-infection with rumen fluke was quantified and its association with liver fluke and management practices was assessed.
\end{abstract}

Methods: A total of 305 sheep flocks were selected ensuring even national representation of the sheep population. Participating farms were asked to complete a survey questionnaire on farm management practices and submit faecal samples during the winter of 2014-2015. Pooled faecal samples were analysed for the presence of $F$. hepatica and coinfection with rumen fluke. Apparent and true prevalence were calculated, additionally, the rate of co-infection with rumen fluke was also obtained. Correlation and regression analyses were used for assessing associations between management practices, liver fluke infection and co-infection with rumen fluke.

Results: The national true prevalence of F. hepatica was $50.4 \%(n=305)$. Regional prevalence varied from $41 \%$ in the east to $52 \%$ in the south. Co-infection with rumen fluke was observed in $40 \%$ of the studied population and correlated with increased F. hepatica egg counts $(\mathrm{OR}=2.9 ; P \leq 0.001)$. Predominant breeds were Suffolk, Texel and Horned Mountain breeds. Beef cattle were the most frequent type of other livestock present on farms and mixed species grazing was frequently reported (73\%). More than half of the flocks reported a mid-to-late lambing period (MarchApril). Use of mountain land for grazing was of $32 \%$. Flukicides were most commonly used twice over the autumnwinter period. Regression analyses highlighted significant association of F. hepatica status, with the presence of other livestock on farm, frequency of flukicides used during the winter and clinical presentation of liver fluke. A significant increase in eggs per gram of faeces was observed in Charollais sheep in comparison with all other breeds. Co-infection with F. hepatica and Calicophoron daubneyi was also significantly associated with the presence of other livestock on the farm, type of flukicide used and clinical fasciolosis.

Conclusions: The present study provides up-to-date information on the prevalence of $F$. hepatica in Irish sheep and adds insight to the epidemiology of the disease. These findings will be useful for designing new holistic control measures for F. hepatica infection.

Keywords: Fasciola hepatica, Sheep, Prevalence, Co-infection, Calicophoron daubneyi, Breed, Treatment, Flukicide, Liver fluke

\footnotetext{
*Correspondence: piamunita@gmail.com

${ }^{1}$ Animal and Grassland Research and Innovation Centre (AGRIC), Teagasc,

Moorepark, Fermoy, County Cork, Ireland

Full list of author information is available at the end of the article
} 


\section{Background}

Fasciola hepatica, commonly known as the liver fluke, is a helminth parasite of mammals and a member of the Class Trematoda $[1,2]$. It infects cattle, sheep, goat, horse, deer and humans as definitive hosts [3]. The parasite has a worldwide distribution and is considered an important disease of domestic livestock, especially in temperate climatic zones [4]. Fasciolosis has been estimated to account for annual losses of $€ 90$ million to the Irish livestock industry and $€ 2.5$ billion worldwide [5].

In sheep, liver fluke infection affects productivity and welfare [3]. It is a predisposing risk factor for mastitis [6] and drop in coagulation parameters [7]. The ingestion of large numbers of infective stages of the parasite can cause a highly pathogenic sub-acute presentation in lambs, characterised by hepatic haemorrhage and lesions, resulting in sudden death $[1,8]$. Inflammatory mediators from liver damage might also affect early pregnancy [8]. Chronic fasciolosis, the most common clinical presentation, might lead to emaciation, especially in more susceptible animals and in ewes in the advanced stages of gestation [8]. In contrast to the dairy and beef sector, the cost of liver fluke in sheep enterprises is largely unquantified at a national and regional level [9].

Fasciola hepatica has an indirect life-cycle, with larval stages depending on a molluscan intermediate host for their development. The intermediate host species is largely determined by geographical location. In Europe, the most important snail in the fluke life-cycle is Galba truncatula [10]. In Ireland, Radix spp. and other genera have also been described as intermediate hosts, in addition to G. truncatula [11]. Temperature and moisture are the most important environmental factors for the presence of G. truncatula and F. hepatica development as wet soils with temperatures higher than $10^{\circ} \mathrm{C}$ are required for their development [2]. The Irish climate provides ideal environmental conditions for $F$. hepatica in winter and early summer. The peak of infection in Irish sheep usually occurs in late winter and spring, following the summer infection of snails [8]. Conventionally control measures against $F$. hepatica chiefly rely on the use of anthelmintics. However, ideally, management practices and treatment should be used strategically, based on diagnosis- and evidence-based control measures for effectively reducing parasite burdens.

Paramphistomes, or rumen flukes, are represented by Calicophoron daubneyi and Paramphistomum leydeni in Ireland; however, the predominant species is $C$. daubneyi $[12,13]$. Rumen flukes infect the same intermediate snail hosts as $F$. hepatica [14]. Infections of both rumen flukes and $F$. hepatica are acquired by ingestion of encysted metacercariae on grass. Probably the biggest difference between the two parasites is their pathology. Following ingestion and excystment, $F$. hepatica will migrate from the intestinal lumen, from the intestinal wall and peritoneum to reach the bile ducts for maturation [3], whereas immature paramphistome will attach to the small intestine mucosa for feeding before reaching the fore stomachs for maturation [15]. In contrast to $F$. hepatica, clinical paramphistomosis is rare, and is chiefly caused by large burdens of juveniles in the small intestine as adults in the forestomachs appear to be well tolerated $[12,15]$. While $F$. hepatica can be treated with a range of flukicides, adult rumen flukes are only susceptible to oxyclozanide, with closantel being reported as having some efficacy against adult stages $[16,17]$. This factor limits its control and increases the possibility of resistance as treatment rotations are not applicable [18]. The possibility that rumen fluke has adapted to the Irish climate more effectively than liver fluke, in addition to the fact that treatment against $F$. hepatica opens up the niche for paramphistomes, may result in the gradual replacement of $F$. hepatica by paramphistomes [19].

A previous $F$. hepatica pilot prevalence study in a small population of Irish sheep confirmed infection in $62 \%$ of animals [20], one of the highest recorded in Europe [9]. There are no up-to-date cross-sectional prevalence studies of $F$. hepatica in Irish sheep. Also, information on the relationship between $F$. hepatica, management factors and paramphistomes on a national scale is scarce. The present study aimed to generate national prevalence data for $F$. hepatica in Irish sheep flocks and to conduct a risk analysis based on management and treatment practices in participating flocks. Additionally, the study aimed to quantify the association and level of co-infection with rumen fluke.

\section{Methods}

\section{Sample population}

The present study was conducted between November 2014 and January 2015, coinciding with the high-risk period for fluke infection in the Irish temperate climate; 2014 was considered to be one of the warmest years in Ireland [21], probably benefiting the parasite. Flocks were recruited using Teagasc (Irish Food and Agriculture Development Authority) networks of Irish sheep farmers via 50 national Teagasc sheep advisors. Additionally, application forms were distributed through Teagasc Newsletters and the Irish Farmer's Journal for circulation within farming and related communities. The application form consisted of a short questionnaire requesting the Teagasc advisor's name, herd number, farmer's name, postal address, GPS coordinates of the farmyard, mobile number, flock size (number 
of breeding animals), lambing season and preferred months of sampling. More than 350 applications were received. A total of 322 flocks were targeted, selected by stratified geographical location and flock size, to represent the national geographic spread according to the Census of Agriculture (2010) [22]. Once flocks were selected, farmers were informed by post and were requested to post back a consent form and dosing protocols. Consent forms were a prerequisite for taking part in the present study and allowed the use of farmer's data in the study. The participation of farms was on a voluntary, non-incentivised basis.

\section{Sample collection}

Sheep faecal samples were submitted between November 2014 and January 2015 to University College Dublin by post in a standardised kit [13], which briefly contained; 20 faecal containers (Sarstedt, Germany), a pre-paid postage envelope, an instruction leaflet and a sample submission form. Farmers were requested to obtain 20 fresh faecal catch samples from 20 different ewes in the flock and place each one in separate faecal container, this, together with flock sample size were determined using the Rogan-Gladen sample size estimator (http://www. ausvet.com.au). Samples were to be posted immediately after collection.

\section{Samples preparation and analyses}

Upon receipt at the laboratory, faecal catch samples from each flock were pooled using $3 \mathrm{~g}$ of faeces from each pot, preparing two composite samples of $30 \mathrm{~g}$, for representing all sampled animals. From each composite, 5 $\mathrm{g}$ of faeces were used to assess the number of liver fluke and rumen fluke eggs $[3,13]$. Results from the faecal egg counts (FECs) were recorded as eggs per gram (epg) of faeces, assuming a test sensitivity of $90 \%$.

\section{Questionnaire}

A questionnaire was designed for the purpose of this study using a web-based survey tool (http://www.surve ymonkey.com). This consisted of questions from a previous study [23] adapted for use on sheep farms. A total of 17 questions consisting of 12 multiple-choice, one ranking question and four open-ended questions, were organised in three sections: (i) farm background; (ii) F. hepatica management; and (iii) additional comments. The entire survey required approximately ten minutes to complete.

The form was reviewed by a group of sheep researchers based in Teagasc before being distributed by post to the participating farms. Prior to distribution, farmers received a text message informing them about the survey and a reminder text message was sent to farmers two weeks after distribution.

\section{Flock classification and management practices}

The classification of $F$. hepatica status (positive or negative) was assigned based on the presence or absence of liver fluke eggs in pooled faecal samples. Classification of co-infection (observed or not observed) was assigned to flocks based on the presence or absence of both $F$. hepatic $a$ and rumen fluke eggs in the pooled samples.

Region (west, east and south) and flock size were obtained at recruitment or from the application form sent by the farmer. Classification by region was based on soil type according to Bloemhoff et al. [23]. Flock size was divided into two categories: $<120$ or $>120$ breeding animals (Table 1). Soil type self-classification was assigned into three categories: 1, dry; 2, damp; and 3, wet soil. Breeds included in the 'other' category (Table 1) included Belclare crosses, Lleyn crosses and mixed flocks with more than one predominant breed.

Details on management practices and dosing regimens were obtained via the questionnaire surveys. Classification of management practices (presence of other livestock in the farm, mixed species grazing, lambing period and mountain or lowland grazing, organic/conventional and slaughter plant feedback are shown in Tables 1 and 2 .

\section{Treatment classification}

Treatment management (Table 2) included: dosing frequency within the year of sampling, type of flukicides most commonly used, flukicides used in autumn and winter during the year of study and frequency of treatment during the period of sampling. Also, the use of treatment in different groups of animals and the rotation of flukicides were considered. Treatment variables derived from the questionnaire and categories are listed in Table 2.

Moreover, active ingredient of flukicides was considered as a variable and categorised as 'used' or 'not used' by each flock. This variable was created from 'type of flukicides most commonly used' answers.

\section{Statistical analyses}

On receipt of the completed questionnaires, answers were manually entered into a web-based tool (http:// www.surveymonkey.com), with the help and inspection of other researchers to verify correct data entry. Coded databases were downloaded into SPSS (IBM, USA) and used for initial descriptive analyses. Collation of the data and graphical representations were done with MS Excel (MS Office version 2010). A map was created in ArcGIS $10.3 \odot$ ESRI, Redland CA, using as backdrop the national sheep population in Ireland, based on the Department of Agriculture, Food and the Marine's Ovine Census data, 2015. A kernel density estimation was applied, with a cell size of 100 metres and a search radius of 10 kilometres. 
Table 1 Sheep flocks management variables and categories derived from survey, percentage of answers and negative and positive infection ratios

\begin{tabular}{|c|c|c|c|c|}
\hline Question & Category & $\begin{array}{l}\text { Answers } \\
\%(n)\end{array}$ & $\begin{array}{l}\text { Negative } \\
\%(n)\end{array}$ & $\begin{array}{l}\text { Positive } \\
\%(n)\end{array}$ \\
\hline \multirow[t]{8}{*}{ Breed } & Horned mountain breed & $11.9(30)$ & $5.9(15)$ & $5.9(15)$ \\
\hline & Suffolk and crosses & $38.1(96)$ & $18.2(46)$ & $19.8(50)$ \\
\hline & Texal and crosses & $24.4(59)$ & $11.1(28)$ & $12.3(31)$ \\
\hline & Cheviot & $7.1(18)$ & $4.4(11)$ & $2.8(7)$ \\
\hline & Leicester and crosses & $4.4(11)$ & $4.4(11)$ & $0(0)$ \\
\hline & Charollais and crosses & $4.8(12)$ & $2.4(6)$ & $2.4(6)$ \\
\hline & Galway and crosses & $0.4(1)$ & $0(0)$ & $0.4(1)$ \\
\hline & Other & $9.9(25)$ & $5.9(15)$ & $3.9(10)$ \\
\hline \multirow[t]{2}{*}{ Flock size } & $<120$ & $53.9(138)$ & $27.3(70)$ & $26.6(68)$ \\
\hline & $>120$ & $46.1(118)$ & $26.6(68)$ & $19.5(50)$ \\
\hline \multirow[t]{5}{*}{ Other livestock present on farm } & None & $25.0(63)$ & $15.1(38)$ & $9.9(25)$ \\
\hline & Beef & $59.9(151)$ & $30.2(76)$ & $29.8(75)$ \\
\hline & Dairy & $1.2(3)$ & $0.8(2)$ & $0.4(1)$ \\
\hline & Horses & $3.6(9)$ & $0.8(2)$ & $2.9(7)$ \\
\hline & Other & $10.3(26)$ & $5.2(13)$ & $5.2(13)$ \\
\hline \multirow{4}{*}{$\begin{array}{l}\text { Same paddock grazing of other livestock } \\
\text { and sheep }\end{array}$} & No other livestock & $24.5(60)$ & $13.9(34)$ & $10.6(26)$ \\
\hline & Same paddock grazing, not at same time & $25.3(62)$ & $10.6(26)$ & $14.7(36)$ \\
\hline & Same paddock grazing, at same time & $47.4(116)$ & $24.9(61)$ & $22.5(55)$ \\
\hline & No & $2.9(7)$ & $1.6(4)$ & $1.2(3)$ \\
\hline \multirow[t]{6}{*}{ Lambing period } & December-January (early) & $1.2(3)$ & $0.8(2)$ & $0.4(1)$ \\
\hline & January-March (early-mid) & $14.9(37)$ & $6.9(17)$ & $8.1(20)$ \\
\hline & February-March (mid) & $25.8(64)$ & $12.9(32)$ & $12.9(32)$ \\
\hline & March-April (mid-late) & $52.4(130)$ & $27.4(68)$ & $25.0(62)$ \\
\hline & April-June (late) & $3.2(8)$ & $2.8(7)$ & $0.4(1)$ \\
\hline & Other & $2.4(6)$ & $1.2(3)$ & $1.2(3)$ \\
\hline \multirow[t]{4}{*}{ Sheep grazing land } & Only lowland & $67.5(168)$ & $36.6(91)$ & $30.9(77)$ \\
\hline & Lowland (> 50\%) and mountain & $18.5(46)$ & $7.6(19)$ & $10.8(27)$ \\
\hline & Lowland and mountain (> 50\%) & $12.9(32)$ & $6.8(17)$ & $6.0(15)$ \\
\hline & Only mountain & $1.2(3)$ & $0.8(2)$ & $0.4(1)$ \\
\hline \multirow[t]{3}{*}{ Organic farm } & Organic certified & $2.9(7)$ & $1.2(3)$ & $1.6(4)$ \\
\hline & Organic not certified & $7.3(18)$ & $3.3(8)$ & $4.1(10)$ \\
\hline & No & $89.8(221)$ & $47.2(116)$ & $42.7(105)$ \\
\hline
\end{tabular}

Apparent prevalence (Ap) was calculated based on the percentage of flocks recording positive FECs in the study. For the calculation of true prevalence (Tp) the RoganGladen estimator in survey toolbox version 1.04 (http:// www.ausvet.com.au) was used, assuming a test sensitivity of $90 \%$ and specificity of $99.9 \%$. Prevalence was calculated both on a national and regional basis. Co-infection was calculated on the percentage of flocks where both parasites were detected in the composite sample.

Normality of the data was assessed visually using ladder of powers histograms, with normality of residuals assessed using normal probability plots and kernel density estimate plots constructed in Stata version 13 (StataCorp, USA). Pearson's chi-square test was used for evaluating the univariable correlations between every categorical variable. Wilcoxon signed-rank test was applied for comparing the total sum of eggs per gram per region. Pearson's chi-square, Wilcoxon test and final regression models were carried out using Stata 13. All regression models were constructed by completing a chisquared univariable analysis examining all two-way associations. Those variables recording $P$-values of $\leq 0.15$ in univariable analyses were included in multivariable models. A manual backwards elimination with a forward step was used to build models; some variables, based on the potential association with $F$. hepatica, were included in final models even if they did not show significance in the initial Pearson's analysis (forced into the models). Both FEC categorisation (positive $v s$ negative) and actual FEC were used as the categorical and continuous dependent 
Table 2 Liver fluke treatment variables and categories derived from survey, percentage of answers and negative and positive infection ratios

\begin{tabular}{|c|c|c|c|c|}
\hline Question & Category & $\begin{array}{l}\text { Answers } \\
\%(n)\end{array}$ & $\begin{array}{l}\text { Negative } \\
\%(n)\end{array}$ & $\begin{array}{l}\text { Positive } \\
\%(n)\end{array}$ \\
\hline \multirow[t]{4}{*}{ IIIness or death due to liver fluke in last 5 years } & Yes, multiple occasions & $4.7(12)$ & $0.4(1)$ & $4.4(11)$ \\
\hline & Yes, rarely & $34.0(86)$ & $15.4(39)$ & $18.6(47)$ \\
\hline & No & $51.8(131)$ & $31.6(80)$ & $20.2(51)$ \\
\hline & Do not know & $9.5(24)$ & $4.7(12)$ & $4.7(12)$ \\
\hline \multirow[t]{5}{*}{ Liver fluke dosing regime } & Do not dose & $4.8(12)$ & $3.6(9)$ & $1.2(3)$ \\
\hline & Every month to six weeks in autumn & $20.7(52)$ & $9.2(23)$ & $11.6(29)$ \\
\hline & Once over the autumn winter period & $17.9(45)$ & $10.4(26)$ & $7.8(19)$ \\
\hline & Twice over the autumn winter period & $49.4(18)$ & $25.1(63)$ & $24.3(61)$ \\
\hline & Other & $7.2(18)$ & $4.0(10)$ & $3.2(8)$ \\
\hline \multirow[t]{5}{*}{ Flukicides most commonly used } & No flukicides used & $3.2(8)$ & $2.4(6)$ & $0.8(2)$ \\
\hline & One adulticide & $2.8(7)$ & $2.0(5)$ & $0.8(2)$ \\
\hline & Two adulticides & $2.0(5)$ & $0.8(2)$ & $1.2(3)$ \\
\hline & One active against more than one stage & $36.8(91)$ & $19.0(47)$ & $17.8(44)$ \\
\hline & More than one active against more than one stage & $55.1(136)$ & $27.1(67)$ & $27.9(69)$ \\
\hline \multirow{5}{*}{ Flukicides used between September 2014 and April 2015} & No flukicides used & $0.9(2)$ & $0.4(1)$ & $0.4(1)$ \\
\hline & One maturicide & $8.1(18)$ & $5.4(12)$ & $2.7(6)$ \\
\hline & Two maturicides & $2.7(6)$ & $1.8(4)$ & $0.9(2)$ \\
\hline & One active against more than one stage & $51.6(115)$ & $25.1(56)$ & $26.5(59)$ \\
\hline & More than one active against more than one stage & $36.8(82)$ & $17.9(40)$ & $18.8(42)$ \\
\hline \multirow{6}{*}{$\begin{array}{l}\text { Flukicides frequency used between September } 2014 \text { and } \\
\text { April } 2015\end{array}$} & 0 times & $0.4(1)$ & $0(0)$ & $1.0(0.4)$ \\
\hline & 1 time & $19.1(44)$ & $13.0(30)$ & $6.1(14)$ \\
\hline & 2 times & $39.8(92)$ & $21.7(50)$ & $18.2(42)$ \\
\hline & 3 times & $26.4(61)$ & $11.7(27)$ & $14.7(34)$ \\
\hline & 4 times & $13.4(31)$ & $4.8(11)$ & $8.7(20)$ \\
\hline & 5 times & $0.9(2)$ & $0(0)$ & $0.9(2)$ \\
\hline \multirow{2}{*}{$\begin{array}{l}\text { Administration of flukicides to animals separated in } \\
\text { groups }\end{array}$} & No & $93.0(214)$ & $48.3(111)$ & $44.8(103)$ \\
\hline & Yes & $7.0(16)$ & $3.0(7)$ & $4.0(9)$ \\
\hline \multirow[t]{6}{*}{ Product rotation } & Same product every year & $19.6(48)$ & $10.2(25)$ & $9.4(23)$ \\
\hline & Product rotation every year or every second year & $62.0(152)$ & $29.8(73)$ & $32.2(79)$ \\
\hline & $\begin{array}{l}\text { Use of any available product from veterinarian or } \\
\text { licenced merchant }\end{array}$ & $6.1(15)$ & $3.7(9)$ & $2.5(6)$ \\
\hline & Use of the cheapest or best deal product & $3.7(9)$ & $2.0(5)$ & $1.6(4)$ \\
\hline & Use of product recommended by veterinarian & $4.1(10)$ & $2.5(6)$ & $1.6(4)$ \\
\hline & No dosing & $4.5(11)$ & $3.3(8)$ & $1.2(3)$ \\
\hline \multirow{3}{*}{$\begin{array}{l}\text { Information received from slaughter plant on liver fluke } \\
\text { status }\end{array}$} & Yes, majority of animals with liver fluke evidence & $1.7(4)$ & $0.4(1)$ & $1.3(3)$ \\
\hline & Yes, minority of animals with liver fluke evidence & $25.8(60)$ & $12.0(28)$ & $13.7(32)$ \\
\hline & $\begin{array}{l}\text { Never received liver fluke information from slaughter } \\
\text { plants }\end{array}$ & 72.5 (169) & $38.6(90)$ & $33.9(79)$ \\
\hline
\end{tabular}

variable for logistic and linear regression, respectively. Logistic regression was used for the co-infection model.

\section{Results}

\section{Descriptive analyses}

From the 322 flocks initially contacted a total of 305 flocks participated in the present study (Fig. 1). This yielded a sufficient sample size to achieve a $95 \%$ confidence level and precision of $5 \%$, for a national sheep population of approximately 34,500 flocks with an expected national prevalence of $70 \%$. The response rate for the survey was $83 \%$, corresponding to 252 completed surveys.

The predominant breeds in the participating flocks were Suffolk and crosses (38.1\%), Texal and crosses (24.4\%) and Horned mountain (11.9\%) (Table 1), accounting for $74.4 \%$ of flocks nationally. Each of the other specified breeds in the questionnaire (Cheviot and crosses, 


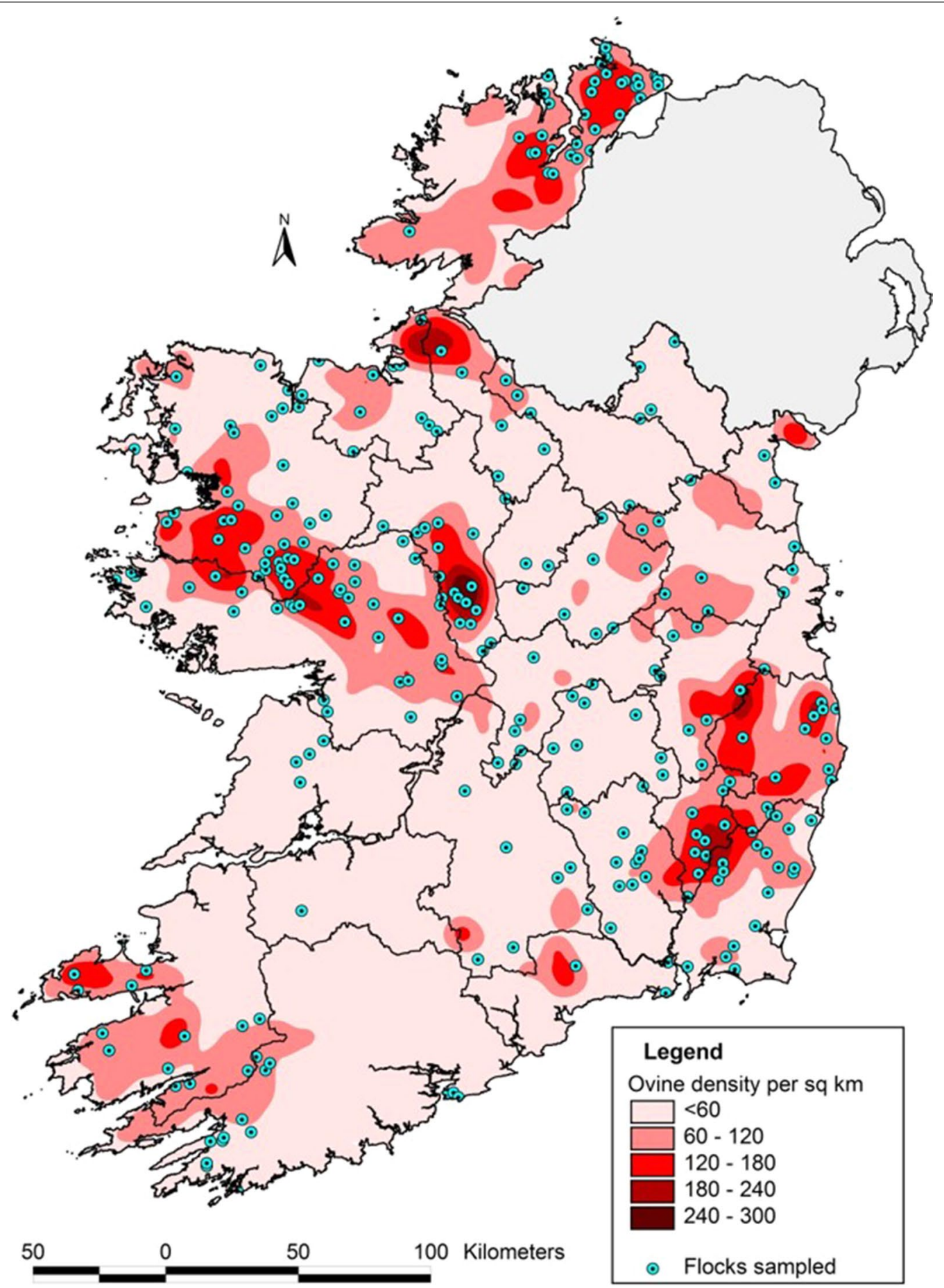

Fig. 1 Map showing geographical distribution of participating flocks (blue dots) over national sheep density [22]

Leicester and crosses, Charollais and crosses and Galway and crosses) reported percentages below 10\% (Table 1). Flocks classified as 'other' breeds showed the highest representation (56\%) in the east region. Suffolk and Texal breeds showed the highest rates of $F$. hepatica infection
(19.8\% and $12.3 \%$, respectively) (Table 1). Co-infection rates between breeds varied from $51 \%$ (Texal and crosses) to $0 \%$ (Leicester and Galway crosses) (data not shown).

Beef cattle were the most frequent type of 'other livestock' present on the same farm (Table 1), $25 \%$ of the 
farms did not report any other livestock. In general, the presence of other livestock on the same farm was not correlated with $F$. hepatica infection or co-infection with rumen fluke $(P>0.05)$ in the Chi-squared analysis (Additional file 1: Table S1).

Predominantly, grazing practices included a mix of species, $72.7 \%$ of the farms reported using the same grazing paddocks for different species, either at the same time (47.4\%) or at different times (25.3\%) (Table 1). Paddock grazing of sheep together with other livestock did not show any correlation with $F$. hepatica or co-infection (Additional file 1: Table S1).

More than half of the participating farms reported lambing between March and April (mid-late) $(52 \%, n=130)$ (Table 1), with lambing season correlated with geographical region $(P=0.012)$ (Additional file 1: Table S1), i.e. flocks located in the western part of the country were chiefly lambing during mid late season (35\%).

Almost $70 \%$ of the flocks grazed on lowland only, while partial or complete use of mountain land for foraging was practiced by the remainder (Table 1 ). There was no correlation between this variable and infection with $F$. hepatica (Additional file 1: Table S1) or co-infection with rumen fluke. However, the grazing of mountain or low land pastures was correlated with region $(P<0.0001)$ and breed $(P<0.0001)$ (Additional file 1: Table S1). Flocks foraging in mixed low and mountain land were predominantly located in the west $(23 \%)$ while flocks grazing only on mountain land were mostly located in the east and south (1.2\%). Horned mountain and Cheviot breeds grazed primarily on mountain land and a small proportion of low land, with every other breed grazing mostly on low land pastures.

According to the farmers' own classification of soil type in grazing areas, waterlogged zones were reported across all seasons. Most of the farms reported wetter land during winter and drier conditions in summer, with transitions during autumn and spring.

Only $10 \%$ of flocks were classified as organic (Table 1). $73 \%$ of the flocks reported never have received any liver fluke feedback from the slaughter house (Table 2).

\section{Liver fluke management and treatment practices}

More than half of the participating flocks did not register critical illness or death due to liver fluke in the last five years (Table 2). This variable proved to be correlated with F. hepatica status $(P=0.002)$ and co- infection $(P=0.006)$ (Additional file 1: Table S1). Of the 131 flocks with no illness or death in the past five years, 80 were $F$. hepaticanegative according to faecal egg count.

The most common dosing regimen recorded was twice over the autumn and winter period (Table 2). Nine negative herds did not use any treatment (Table 2). The majority of $F$. hepatica-negative herds stated treating with flukicides once $(10.4 \%)$ or twice $(25 \%)$ over the autumn and winter period (Table 2). Fasciola hepaticapositive herds treated every month or six weeks during the autumn (12\%) or twice during the autumn and winter period (24\%) (Table 2). Nine F. hepatica-positive farms did not use any dosing treatment (Table 2).

The majority (92\%) of farmers used flukicides active against immature as well as adult stages of the parasite (Table 2). This was true for both $F$. hepatica-negative and positive flocks. The most commonly used product was closantel, followed by oxyclozanide and triclabendazole. No significant differences between positive and negative flocks and the flukicides they used were observed. A bar graphic representing the frequencies of the most commonly used flukicides in positives and negative herds is shown in Fig. 2.

Flukicides used between March and April were most commonly products active against immature and mature flukes. The majority $(85 \%)$ of these treatments were used between one and three times during this period (Table 2) with $46 \%$ in negative flocks and $39 \%$ in positive flocks, respectively. The type of flukicide used between March and April was correlated with treatment frequency $(P \leq 0.0001)$ and liver fluke status $(P=0.025)$ (Additional file 1: Table S1).

As shown in Table 2, 93\% of the flocks did not treat animals in separated sub-groups. However, half of the flocks which treated in groups were located in the western region.

\section{Prevalence and co-infection}

Fasciola hepatica egg counts (Fig. 3) were not normally distributed and ranged between 0-137 epg. The highest egg counts and highest total sums of epg were recorded in the west of the country. The overall median was zero (0), as zero (0) was the most common faecal egg count registered, regional medians are shown in Table 3.

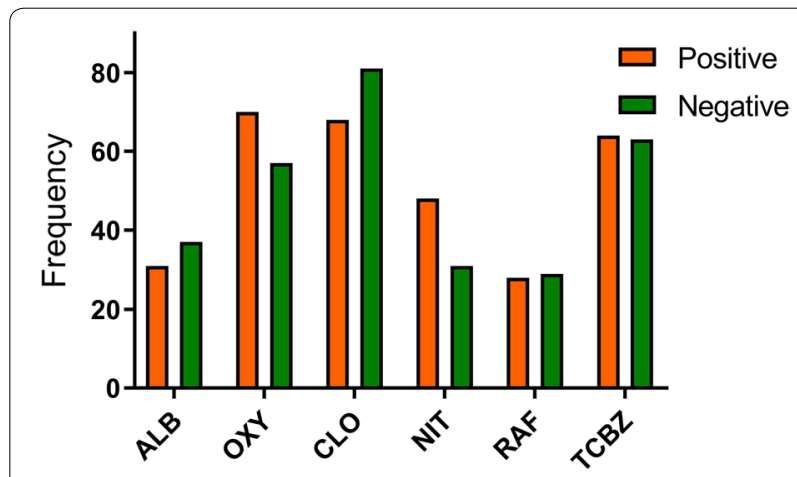

Fig. 2 Bar graphic showing the frequencies of the flukicides most commonly used in positive and negative flocks. Abbreviations: ALB, albendazole; OXY, oxyclozanide; NIT, nitroxynil; RAF, rafoxanide; TCBZ, triclabendazole 


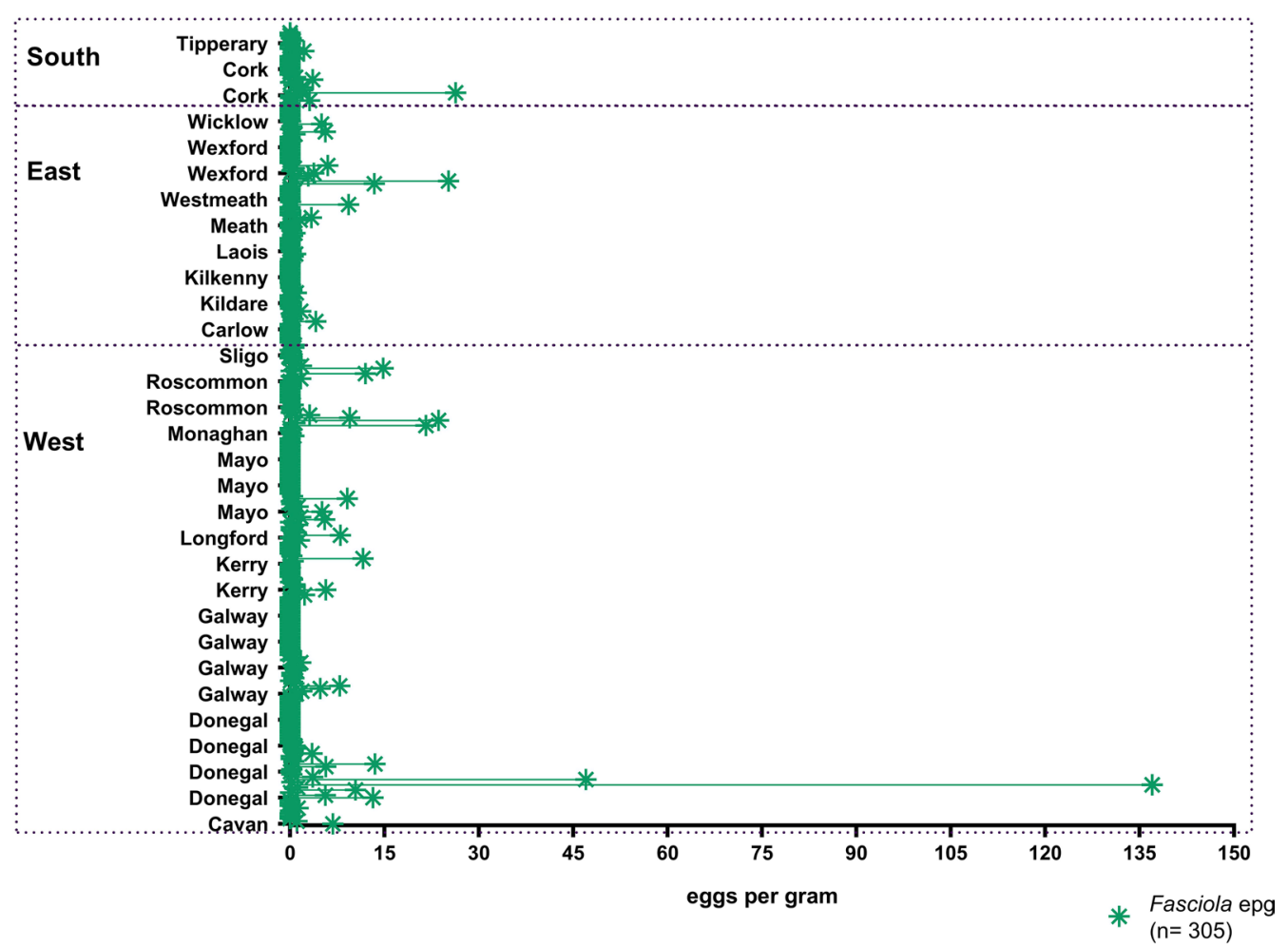

Fig. 3 Dot plot representing Fasciola hepatica eggs per gram in counties and regions

Table 3 Regional and national classification of eggs per gram (epg), total sum of epg, apparent prevalence (Ap), true prevalence (Tp), 95\% confidence interval (Cl), co-infection and flock size rate

\begin{tabular}{lllll}
\hline & $\begin{array}{l}\text { West } \\
(n=183)\end{array}$ & $\begin{array}{l}\text { East } \\
(n=96)\end{array}$ & $\begin{array}{l}\text { South } \\
(n=26)\end{array}$ & $\begin{array}{l}\text { National } \\
(n=305)\end{array}$ \\
\hline Median epg & 0 & 0 & 0.1 & 0 \\
Total sum of epg & 428.6 & 95.4 & 39.7 & 563.7 \\
Ap (\%) & 47.5 & 41.2 & 52.0 & 45.9 \\
$\operatorname{Tp}(95 \%$ CI) (\%) & 53.1 & 45.7 & 55.1 & 50.4 \\
& $(45.1-61.3)$ & $(35.1-56.9)$ & $(34.9-75.2)$ & $(44.3-56.8)$ \\
Co-infection (\%) & 43.3 & 35.1 & 40.0 & 40.3 \\
Flock size range & $10-550$ & $22-560$ & $17-500$ & $10-560$ \\
\hline
\end{tabular}

The national apparent prevalence (Ap) and estimated true prevalence (Tp) of . hepatica were $45.9 \%$ and $50.4 \%$ (95\% CI: 44.3-56.8\%) (Table 3), respectively, assuming a test sensitivity of $90 \%$ and specificity of $99.9 \%$. The prevalence across different regions varied from $41.2 \%$ in the east and 52\% in the south (Table 3).

Paramphistome and $F$. hepatica co-infection was observed in $40.3 \%$ of the study population. Regionally, it ranged from $35.1 \%$ to $43.3 \%$ (Table 3). Only 17 flocks positive to $F$. hepatica did not show co-infection.

\section{Regression analyses}

Logistic regression analysis identified the presence of horses $(\mathrm{OR}=10.8, P=0.035)$ in the participant farms as a risk factor for liver fluke infection, over flocks not sharing land with any other domestic animal species (Table 4). Infection status of horses present in participating farms were not recorded.

In general, treating with flukicides more than once in the period of sampling indicated a higher risk of $F$. hepatica in different degrees. As shown in Table 4, the use of one treatment prior to sampling decreased the risk of a positive FEC when compared to dosing two times $(\mathrm{OR}=0.48, P=0.077)$ or three times $(\mathrm{OR}=0.32$, $P=0.012)$. Also, dosing four times in this period, showed positive odd ratios against dosing twice $(\mathrm{OR}=2.3$, $P=0.067)$ or once $(\mathrm{OR}=4.8, P=0.003)$.

Presentation of multiple clinical cases in the past five years proved to be a predictive factor for liver fluke infection. The odds ratio of this variable against no clinical disease was almost $20(P=0.006)$ (Table 4). However, farms which reported no clinical episodes of $F$. hepatica presented higher risk $(\mathrm{OR}=12.92, P=0.028)$ than those reporting a clinical event rarely $(\mathrm{OR}=10.54, P=0.030)$ (Table 4).

Linear regression analyses of liver fluke egg counts showed that flocks co-infected with liver and rumen fluke 
Table 4 Multivariable logistic regression of F. hepatica status (dependent variable) across other livestock present in farm, treatment count between September 2014 and April 2015 and illness or death due to F. hepatica (independent variables)

\begin{tabular}{|c|c|c|c|c|}
\hline Independent variable & Odds ratio & $95 \% \mathrm{Cl}$ & $P$-value & $\begin{array}{l}\text { Model } \\
\text { (P-value) }\end{array}$ \\
\hline \multicolumn{4}{|l|}{ Other livestock present in farm } & \multirow{12}{*}{$\begin{array}{l}\text { Other livestock present in farm vs treat } \\
\text { count before sample vs illness or death } \\
\text { due to liver fluke }(P=0.0020)\end{array}$} \\
\hline Horses vs none & 10.78 & $1.18-98.37$ & 0.035 & \\
\hline Horses vs beef & 9.71 & $0.99-94.80$ & $0.076^{*}$ & \\
\hline \multicolumn{4}{|c|}{ Treatment frequency before sampling } & \\
\hline 1 treatment vs 2 & 0.48 & $0.21-1.08$ & $0.077^{*}$ & \\
\hline 1 treatment vs 3 & 0.32 & $0.13-0.78$ & 0.012 & \\
\hline 4 treatments vs 2 & 2.30 & $0.94-5.60$ & $0.067^{*}$ & \\
\hline 4 treatment vs 1 & 4.81 & $1.68-13.77$ & 0.003 & \\
\hline \multicolumn{4}{|l|}{ Illness or death due to liver fluke } & \\
\hline Multiple occasions vs none & 19.74 & $2.37-164.11$ & 0.006 & \\
\hline Multiple occasions vs rarely & 10.54 & $1.25-88.97$ & 0.030 & \\
\hline Multiple occasions vs not known & 12.92 & $1.33-125.86$ & 0.028 & \\
\hline
\end{tabular}

Abbreviation: $\mathrm{Cl}$, confidence interval

*Tendency

presented higher $F$. hepatica egg counts (Coefficient $=2.9$, $P<0.001)$ than flocks presenting liver fluke infection only (Table 5). Also, linear regression coefficients revealed higher eggs per gram values for Charollais flocks over flocks of any other breed. Suffolk and 'other' breed flocks showed higher eggs per gram counts than Horned mountain breed flocks (Table 5). Additionally, as shown in Table 5, flocks lambing between March and April (mid to late lambing season) showed an increase in almost 2 epg in comparison with flocks lambing between February and March (mid lambing season) (Coefficient $=1.97$, $P=0.02$ ). Also, the combined use of mountain and lowland for grazing increased the numbers of epg by $2.5 \mathrm{com}-$ pared with flocks grazing lowlands only (Table 5).

As mentioned above, logistic regression highlighted increased risk of infection with the use of more than one treatment before sampling (Table 5). The same was observed in the continuous analysis, i.e. higher egg counts were positively correlated with treatment frequency (Table 5). Also, the manifestation of clinical disease showed a tendency for higher epg (Table 5), complementing the logistic regression results (Table 4).

Multivariable logistic regression for co-infection of liver and rumen fluke (Table 6) included flukicides most commonly used, summer soil type, other livestock present on farm and $F$. hepatica clinical presentation. There was an increased risk of co-infection $(P=0.051)$ in sheep flocks maintained with horses on the same farm, as was observed in the F. hepatica logistic regression (Table 4). Also, the presentation of illness or death due to liver fluke displayed higher odds ratios of co-infection than not presenting clinical infection. Finally, a tendency of higher risk of co- infection was observed in flocks commonly treated with flukicides in comparison with no treatment (Table 6).

\section{Discussion}

There is no doubt of the impact that liver fluke can have on the health and welfare of ruminants, especially in temperate climatic zone like Ireland. The parasite also represents a major economic concern for ruminant production systems. Effective strategic control measures should be based on knowledge of local factors, incidence and management practices [24]. The present study aimed to determine the national prevalence of liver fluke in Irish sheep and to investigate its correlation with common farm management practices. In addition, inclusion of the national co-infection rate with paramphistomes facilitated investigation of risk factors for both trematodes. A previous study, conducted in a pilot area, reported a $62 \%$ liver fluke prevalence in Irish sheep [20]. This study represented just $7.1 \%$ of the national sheep population in the west of the country. The present study which included data collected in the whole country, estimated a national true prevalence of around $50 \%$.

Recent liver fluke prevalence studies published elsewhere have reported infection rates of $41 \%$ in dairy cows in Switzerland [25], 64\% in Mexico [26], and 57\% in Poland [27]. These studies were based on bulk tank milk ELISA tests for the detection of $F$. hepatica exposure rather than active infection indicated by the presence of eggs in the faeces. The specificity of the FEC test is $100 \%$, although, its sensitivity can be lower than $81 \%$ [28] and is dependent on the volume of sample analysed [29]. Therefore, the national 
Table 5 Multivariable linear regression of F. hepatica eggs per gram (dependent variable) across breed, treatment counts before sampling, flock size, lambing period, sheep grazing land, winter soil and illness or death due to F. hepatica (independent variables)

\begin{tabular}{|c|c|c|c|c|}
\hline Independent variable & Coefficient & $95 \% \mathrm{Cl}$ & $P$-value & $\begin{array}{l}\text { Model } \\
\text { (P-value) }\end{array}$ \\
\hline Co-infection (observed vs not-observed) & 2.90 & $1.44-4.35$ & $<0.001$ & \multirow{21}{*}{$\begin{array}{l}\text { Co-infection vs breed vs treat count before } \\
\text { sampling vs flock size vs lambing period vs } \\
\text { grazing land type vs winter soil vs illness or } \\
\text { death due to liver fluke }(P=0.0001)\end{array}$} \\
\hline Breed & & & & \\
\hline Charollais vs mountain breed & 7.70 & $3.48-11.93$ & $<0.001$ & \\
\hline Charollais vs Suffolk & 4.99 & $1.43-8.56$ & 0.006 & \\
\hline Charollais vs Texal & 5.13 & $1.47-8.79$ & 0.006 & \\
\hline Charollais vs Cheviot & 6.34 & $1.67-11.01$ & 0.008 & \\
\hline Charollais vs Leicester & 6.28 & $1.36-11.21$ & 0.013 & \\
\hline Charollais vs Galway & 12.79 & $1.93-23.64$ & 0.021 & \\
\hline Charollais vs other breeds & 4.79 & $0.71-8.87$ & 0.022 & \\
\hline Mountain breed vs Suffolk & -2.72 & $-5.52-0.09$ & $0.057^{*}$ & \\
\hline Mountain breed vs other breeds & -3.17 & $-6.63-0.29$ & $0.073^{*}$ & \\
\hline \multicolumn{4}{|l|}{ Treatment frequency before sampling } & \\
\hline 4 treatments vs 1 & 3.38 & $0.43-6.34$ & 0.025 & \\
\hline 4 treatments vs 2 & 3.65 & $1.18-6.12$ & 0.004 & \\
\hline 4 treatments vs 3 & 3.33 & $0.76-5.89$ & 0.011 & \\
\hline \multicolumn{4}{|l|}{ Lambing period } & \\
\hline March-April (mid-late) vs February-March (mid) & 1.97 & $0.31-3.65$ & 0.021 & \\
\hline \multicolumn{4}{|l|}{ Sheep grazing land } & \\
\hline Lowland and mountain vs lowland & 2.54 & $0.60-4.49$ & 0.011 & \\
\hline \multicolumn{4}{|l|}{ Illness or death due to liver fluke in last 5 years } & \\
\hline $\begin{array}{l}\text { No vs several } \\
\text { No vs rarely }\end{array}$ & $\begin{array}{l}-3.82 \\
-1.38\end{array}$ & $\begin{array}{l}-7.80-0.17 \\
-2.89--0.01\end{array}$ & $\begin{array}{l}0.060^{*} \\
0.072^{*}\end{array}$ & \\
\hline
\end{tabular}

Abbreviation: $\mathrm{Cl}$, confidence interval

*Tendency

Table 6 Multivariable logistic regression of liver fluke and rumen fluke co-infection (dependent variable) across flukicides most commonly used, summer grazing soil scale other livestock present in farm and illness or death due to F. hepatica (independent variables)

\begin{tabular}{llccl}
\hline $\begin{array}{l}\text { Independent variable } \\
\text { Flukicides most commonly used }\end{array}$ & Odds ratio & $95 \% \mathrm{Cl}$ & $P$-value & $\begin{array}{l}\text { Model } \\
(P \text {-value })\end{array}$ \\
$\begin{array}{l}\text { More than one active against more than one stage vs } \\
\text { no treatment }\end{array}$ & 6.74 & $0.75-60.30$ & $0.088^{*}$ & $\begin{array}{c}\text { Flukicides most commonly used vs } \\
\text { summer soil type vs other livestock } \\
\text { present in farm vs illness or death due } \\
\text { to liver fluke }(P=0.0458)\end{array}$ \\
$\begin{array}{l}\text { Other livestock present in farm } \\
\text { Horses vs none }\end{array}$ & 4.95 & $0.99-24.62$ & $0.051^{*}$ & \\
$\begin{array}{l}\text { IIness or death due to liver fluke in last 5 years } \\
\text { Multiple occasions vs rarely }\end{array}$ & 5.49 & $1.09-27.53$ & 0.039 & 0.008 \\
$\begin{array}{l}\text { Multiple occasions vs no } \\
\text { Multiple occasion vs not known }\end{array}$ & 8.54 & $1.75-41.70$ & 0.012 & $1.64-59.22$ \\
\hline
\end{tabular}

Abbreviation: $\mathrm{Cl}$, confidence interval

*Tendency

prevalence in sheep flocks determined in the present study should be considered as a conservative estimate as the test only identifies sexually mature stages of the parasite.

The comparatively high prevalence reported in the present study can be explained by the temperate climate typical for Ireland as it provides optimum conditions for G. truncatula and the environmental stages of F. hepatica to thrive and infect ruminants. A higher total epg count was found in the West, with highest epgs seen in County Donegal (Fig. 3). In contrast the highest rate of infection 
was recorded in the south of the country (Table 3). The reason for this could be that the northern and western parts of the country are under a stronger maritime influence [30]. Other potential causes could be differences in treatments applied, as correlations were found between region, dosing regimens, frequency of treatment and other treatment variables (Additional file 1: Table S1). Although these effects were not detected in the regression analyses, it is possible that differences in regional treatments could have an effect in the number of eggs found. The high epg observed in County Donegal are alarming and indicate that the disease should be closely monitored in the region.

With regard to rumen fluke, a true prevalence of $86 \%$ was reported in the same study population [13] suggesting a relative competitive advantage of paramphistomes over $F$. hepatica, as they share the same intermediate host for completion of their life-cycle. A reason could be the frequent use of flukicides which are not effective against paramphistomes. It has been found that where Fasciola gigantica and paramphistomes co-occur, a larger proportion of animals excrete paramphistome eggs as compared to Fasciola eggs [31]. Yet, no differences in the prevalence of $C$. daubneyi and $F$. hepatica have been found in snail populations in France [32], However, in the UK, equivalent prevalence levels of $C$. daubneyi and $F$. hepatica within G. truncatula populations were associated with higher rumen fluke egg outputs and lower $F$. hepatica egg outputs from livestock grazing the snail habitats [33]. Rondelaud et al. [34] reported a faster development of one parasite over the other in co-infected G. truncatula, suggesting competition between these parasites in the intermediate host. Yet many questions remain to be answered regarding the relationship between paramphistomes, $F$. hepatica and their intermediate and final hosts. Further studies on the host competence of the various snails that occur in Ireland are also required and would add important information to the epidemiology of flukes under current and potential future environmental conditions.

A significant correlation was found between Fasciola hepatica and co-infection $(P=0.001)$, probably because the categorisation of one variable depended on the other and only 17 flocks were infected with $F$. hepatica alone. As both parasites share the same intermediate host, their development in the snail and infection of the final host is clearly linked. Additionally, the presence of co-infection increased $F$. hepatica FEC by 2.9 epg $(\mathrm{P} \leq 0.001)$ and similar findings were observed in Welsh flocks [35].

As mentioned before, generally, most epidemiological studies on $F$. hepatica focus on dairy cows, yet, reports of risk factors associated with $F$. hepatica infection, intermediate and final hosts are currently limited. In the present study, the presence of other livestock on farm was a risk factor for infection with liver fluke (horses, $P=0.035$ ) (Table 4) and co-infection with rumen fluke respectively (horses, $P=0.051$ ) (Table 6). This has not been previously reported. Nonetheless, previous studies indicate the importance of determining ecological dynamics in multihost parasite species [36-38]. Defining hosts-parasite interactions and identifying the hosts for the parasite [39, 40] would impact on control regimens applied to susceptible populations, as these factors contribute to the abundance and distribution of the disease. The susceptibility of horses to $F$. hepatica has been widely reported [3, 41, 42], and an abattoir study in Ireland, reported a F. hepatica prevalence of $9.5 \%$ in horses [43]. On the other hand, attempts to experimentally infect horses have failed [44, 45]. The findings of the present study and the literature strongly suggest the necessity for further investigations in the multi-host-parasite interactions for improvement in control measures. Additionally, these finding highlight the possible role of horses and other species, in the transmission of the liver fluke [13].

The majority of flocks enrolled in the present study were treated with flukicides with only $5 \%$ not using any type of flukicide for the control of $F$. hepatica. Although, differences between positive and negative flocks and flukicide were observed, these differences were not significant in the final correlation models. Most importantly, F. hepatica was present in the majority of the flocks regardless of treatment. Beesley et al. in 2017 [9] identified 20 reports of triclabendazole resistance in sheep within Europe. In Ireland, triclabendazole resistance has also been reported [46-48]. In contrast, other flukicides, such as nitroxynil [47] and closantel [49], seem to have retained their efficacy so far.

An important co-infection risk factor reported in the present study, was the use of triclabendazole. This result was expected, as this drug is not effective against paramphistomes. Closantel and oxyclozanide have shown to be effective parasiticides active only on adult paramphistome $[16,17]$. Although this flukicide was commonly chosen by farmers (Fig. 2) in the present study, other flukicides such as; nitroxynil, rafoxanide and triclabendazole, were also considered within this variable, possibly justifying our findings.

Charollais and crosses sheep as a predominant breed in Irish flocks had increased eggs per gram per sample, in comparison to all other breeds. Remarkably, in Ireland this same effect was revealed in regard to rumen fluke [13]; however, Suffolk breed FECs showed to be significantly higher than other breeds. The susceptibility of Suffolk to helminth infections has been described in Ireland $[50,51]$ and internationally [52]. Nevertheless, no relationships between $F$. hepatica and Charollais breed have been found in the literature. However, increased genetic 
susceptibility in Charollais sheep to Toxoplasma gondii has been described [53] and also, increased sero-prevalence of T. gondii in Charollais lambs has been described [54]. Investigation on $F$. hepatica shedding of eggs in Charollais sheep should be carried out to confirm this finding.

As expected, the clinical presentation of $F$. hepatica correlated with infection $(P=0.002)$ demonstrating a good understanding of the clinical presentation by farmers and the proper diagnosis of the disease. This relationship was equally observed in multivariable $F$. hepatica and co-infection models.

At present, studies in the epidemiological aspects of $F$. hepatica in Irish sheep regarding the management and treatment practices are lacking. The present study estimated the prevalence of $F$. hepatica and its co-infection with rumen fluke based on recruiting a nationally representative flock population. Therefore, the results presented here are suitable for a better comprehension of the actual situation of these parasites in Ireland. The present study also provides a vision of the issues that require deeper knowledge for controlling fluke in sheep, especially under climate challenges.

\section{Conclusions}

The present study provides a cross-sectional national insight into the prevalence of $F$. hepatica and co-infection with rumen fluke in sheep. Also, it provides risk factor analyses of management practices and dosing regimens. This study revealed high prevalence of the liver fluke in Irish sheep flocks. The co-infection of $F$. hepatica and rumen fluke was found to be associated with higher $F$. hepatica egg counts in sheep. Associations of liver fluke infection with horses present on farms and with Charollais breed are novel findings, although the implications of these outcomes remain to be elucidated. The increase of anthelmintic resistance worldwide has emphasized the importance of management strategies in parasite control and in that regard, the present study provides possible new lines of research in the presence of both trematodes for a holistic approach for the control of both diseases.

\section{Supplementary information}

Supplementary information accompanies this paper at https://doi. org/10.1186/s13071-019-3779-y.

Additional file 1. Univariable Pearson's chi-square analysis of independent categorical variables.

\section{Abbreviations}

epg: eggs per gram; Ap: apparent prevalence; Tp: true prevalence.

\section{Acknowledgments}

The authors would like to acknowledge the Irish Department of Agriculture, Food and the Marine for acting as a funding source for this research. Likewise, to recognise the Teagasc drystock advisors for their help in the farmers' recruitment process. Most especially, we wish to distinguish the participant farmers, who enthusiastically submitted samples and completed questionnaires to allow us to complete this national study. Finally, we would to acknowledge Dr Elizabeth Earle for their assistance in the design of the survey and Dr Annetta Zintl for their constructive comments and reviewing of the manuscript

\section{Authors' contributions}

RS, GM and MS designed and conceived the study. NB, AMMI and MPM assembled and distributed sampling kits. RS and MPM designed the survey. MPM recruited farmers, collated and analysed the data and drafted the manuscript. GMCG contributed with the map of participating farms. LEMC contributed to the initial data collation and preliminary analyses. MS carried out sample analyses. RR, MS, RS and GM critically reviewed and revised the manuscript. All authors read and approved the final manuscript.

\section{Funding}

This study was funded by Irish Department of Agriculture, Food and the Marine research stimulus funding; project reference 13/S/405.

\section{Availability of data and materials}

All data are stored in the Teagasc (National Food and Development Authority) database. The datasets used and/or analysed during the present study are available from the corresponding author upon reasonable request.

\section{Ethics approval and consent to participate}

Participating farmers signed a consent form to take part in the study which satisfies the requirement for experimental studies involving client-owned animals, authors must also document informed consent from the client or owner and adherence to a high standard (best practice) of veterinary care.

\section{Consent for publication}

Not applicable.

\section{Competing interests}

The authors declare that they have no competing interests.

\section{Author details}

${ }^{1}$ Animal and Grassland Research and Innovation Centre (AGRIC), Teagasc, Moorepark, Fermoy, County Cork, Ireland. ${ }^{2}$ Department of Biological Sciences, Cork Institute of Technology, Bishopstown, Cork, Ireland. ${ }^{3}$ Centre for Veterinary Epidemiology and Risk Analysis, School of Veterinary Medicine, University College Dublin, Dublin, Ireland. ${ }^{4}$ Generación Empresarial, Apoquindo, Las Condes, 6410 Santiago, Chile. ${ }^{5}$ UCD, School of Veterinary Medicine, University College Dublin, Belfield, Dublin, Ireland.

Received: 27 April 2019 Accepted: 30 October 2019

Published online: 06 November 2019

\section{References}

1. Urquhart G, Armour J, Duncan J, Dunn A, Jennings F. Veterinary parasitology. 2nd ed. Oxford: Blackwell Science; 1996.

2. Borgsteede F. Diseases of dairy animals, parasites, internal: liver flukes. In: Fuquay JW, editor. Encyclopedia of dairy sciences. San Diego: Academic; 2011. p. 264-9.

3. Taylor M, Coop R, Wall R. Veterinary parasitology. 3rd ed. Oxford: Wiley; 2013.

4. Bennema SC, Ducheyne E, Vercruysse J, Claerebout E, Hendrickx G, Charlier J. Relative importance of management, meteorological and environmental factors in the spatial distribution of Fasciola hepatica in dairy cattle in a temperate climate zone. Int J Parasitol. 2011;41:225-33.

5. Animal Health Ireland. Liver Fluke - The facts. 2011. https://online.flipp ingbook.com/view/128755/. Accessed 12 Oct 2019.

6. Mavrogianni VS, Papadopoulos E, Spanos SA, Mitsoura A, Ptochos S, Gougoulis DA, et al. Trematode infections in pregnant ewes can predispose to mastitis during the subsequent lactation period. Res Vet Sci. 2014;96:171-9. 
7. Joachim A, Ali S, Daugschies A. Fasciola hepatica alters coagulation parameters in sheep plasma in vivo and in vitro. Parasitol Res. 2002:89:53-8.

8. Sargison ND, Scott PR. Diagnosis and economic consequences of triclabendazole resistance in Fasciola hepatica in a sheep flock in south-east Scotland. Vet Rec. 2011;168:159.

9. Beesley N, Caminade C, Charlier J, Flynn R, Hodgkinson J, MartinezMoreno A. Fasciola and fasciolosis in ruminants in Europe: identifying research needs. Transb Emerg Dis. 2018;65:199-216.

10. Thomas AP. The Life History of the Liver-Fluke (Fasciola hepatica). J Microbiol Sci. 1883;89:99-133.

11. Relf V, Good B, McCarthy E, de Waal T. Evidence of Fasciola hepatica infection in Radix peregra and a mollusc of the family Succineidae in Ireland. Vet Parasitol. 2009;163:152-5.

12. Zintl A, Garcia-Campos A, Trudgett A, Chryssafidis AL, TalaveraArce S, Fu Y, et al. Bovine paramphistomes in Ireland. Vet Parasitol. 2014;204:199-208.

13. Martinez-Ibeas AM, Munita MP, Lawlor K, Sekiya M, Mulcahy G, Sayers R. Rumen fluke in Irish sheep: prevalence, risk factors and molecular identification of two paramphistome species. BMC Vet Res. 2016;12:143.

14. Martínez-Ibeas AM, González-Warleta M, Martínez-Valladares M, CastroHermida JA, González-Lanza C, Miñambres B, et al. Development and validation of a mtDNA multiplex PCR for identification and discrimination of Calicophoron daubneyi and Fasciola hepatica in the Galba truncatula snail. Vet Parasitol. 2013;195:57-64.

15. O'Shaughnessy J, Garcia-Campos A, McAloon CG, Fagan S, de Waal T, McElroy $\mathrm{M}$, et al. Epidemiological investigation of a severe rumen fluke outbreak on an Irish dairy farm. Parasitology. 2018;145:948-52.

16. Sanabria R, Moreno L, Alvarez L, Lanusse C, Romero J. Efficacy of oxyclozanide against adult Paramphistomum leydeni in naturally infected sheep. Vet Parasitol. 2014:206:277-81.

17. Arias MS, Sanchís J, Francisco I, Francisco R, Piñeiro P, Cazapal-Monteiro C, et al. The efficacy of four anthelmintics against Calicophoron daubneyi in naturally infected dairy cattle. Vet Parasitol. 2013;197:126-9.

18. Naranjo-Lucena A, Corbalán MP, Martínez-lbeas AM, McGrath G, Murray G, Casey M, et al. Spatial patterns of Fasciola hepatica and Calicophoron daubneyi infections in ruminants in Ireland and modelling of C. daubneyi infection. Parasit Vectors. 2018;11:531.

19. Naranjo Lucena A, Munita Corbalán MP, Martínez-Ibeas AM, McGrath G, Sayers R, Mulcahy G, et al. Validation of a spatial liver fluke model under field conditions in Ireland. Geospat Health. 2018;1:7-13.

20. Rinaldi L, Hendrickx G, Cringoli G, Biggeri A, Ducheyne E, Catelan D, et al. Mapping and modelling helminth infections in ruminants in Europe: experience from GLOWORM. Geospat Health. 2015;9:257.

21. McGreevy R. Last year was one of warmest on record in Ireland. The Irish Times. 2015. https://www.irishtimes.com/news/environment/last-yearwas-one-of-warmest-on-record-in-ireland-1.2055389

22. Central Statistics Office. Census of Agriculture 2010. Cork, Ireland; 2012. https://www.cso.ie/en/media/csoie/releasespublications/documents/ agriculture/2010/full2010.pdf

23. BloemhoffY, Forbes A, Danaher M, Good B, Morgan E, Mulcahy G, et al. Determining the prevalence and seasonality of Fasciola hepatica in pasture-based dairy herds in Ireland using a bulk tank milk ELISA. Iran Vet J. 2015;68:16.

24. Greiser-Wilke I, Grummer B, Moennig V. Bovine viral diarrhoea eradication and control programmes in Europe. Biologicals. 2003;31:113-8.

25. Frey CF, Eicher R, Raue K, Strube C, Bodmer M, Hentrich B, et al. Apparent prevalence of and risk factors for infection with Ostertagia ostertagi, Fasciola hepatica and Dictyocaulus viviparus in Swiss dairy herds. Vet Parasitol. 2018:250:52-9.

26. Villa-Mancera A, Reynoso-Palomar A. High prevalence, potential economic impact, and risk factors of Fasciola hepatica in dairy herds in tropical, dry and temperate climate regions in Mexico. Acta Trop. 2019:193:169-75.

27. Kowalczyk SJ, Czopowicz M, Weber CN, Müller E, Nalbert T, Bereznowski A, et al. Herd-level seroprevalence of Fasciola hepatica and Ostertagia ostertagi infection in dairy cattle population in the central and northeastern Poland. BMC Vet Res. 2018;14:131.

28. Mazeri S, Sargison N, Kelly RF, Barend M, Handel I. Evaluation of the performance of five diagnostic tests for Fasciola hepatica infection in naturally infected cattle using a Bayesian no gold standard approach. PLOS ONE. 2016;11:e0161621.

29. Rapsch C, Schweizer G, Grimm F, Kohler L, Bauer C, Deplazes P. Estimating the true prevalence of Fasciola hepatica in cattle slaughtered in Switzerland in the absence of an absolute diagnostic test. Int J Parasitol. 2006;36:1153-8.

30. Met Éireann-The Irish Meteorological Service. Climate of Ireland. 2019. https://www.met.ie/climate.

31. Keyyu JD, Monrad J, Kyvsgaard NC, Kassuku AA. Epidemiology of Fasciola gigantica and amphistomes in cattle on traditional, small-scale dairy and large-scale dairy farms in the southern highlands of Tanzania. Trop Anim Health Prod. 2005;37:303-14.

32. Abrous M, Rondelaud D, Dreyfuss G, Cabaret J. Infection of Lymnaea truncatula and Lymnaea glabra by Fasciola hepatica and Paramphistomum daubneyi in farms of central France. Vet Res. 1999;30:113-8.

33. Jones RA, Williams HW, Dalesman S, Ayodeji S, Thomas RK, Brophy PM The prevalence and development of digenean parasites within their intermediate snail host, Galba truncatula, in a geographic area where the presence of Calicophoron daubneyi has recently been confirmed. Vet Parasitol. 2017;240:68-74

34. Rondelaud D, Vignoles P, Dreyfuss G. Larval trematode infections in Galba truncatula (Gastropoda, Lymnaeidae) from the Brenne Regional Natural Park, central France. J Helminthol. 2016;90:256-61.

35. Jones RA, Brophy PM, Mitchell ES, Williams HW. Rumen fluke (Calicophoron daubneyi) on Welsh farms: prevalence, risk factors and observations on co-infection with Fasciola hepatica. Parasitology. 2017:144:237-47.

36. Morgan ER, Milner-Gulland EJ, Torgerson PR, Medley GF. Ruminating on complexity: macroparasites of wildlife and livestock. Trends Ecol Evol. 2004;19:181-8

37. Woolhouse ME, Taylor LH, Haydon DT. Population biology of multihost pathogens. Science. 2001;292:1109-12.

38. Poulin R, Besson AA, Morin MB, Randhawa HS. Missing links: testing the completeness of host-parasite checklists. Parasitology. 2016;143:114-22.

39. Buhnerkempe MG, Roberts MG, Dobson AP, Heesterbeek H, Hudson PJ, Lloyd-Smith JO. Eight challenges in modelling disease ecology in multihost, multi-agent systems. Epidemics. 2015;10:26-30.

40. Walker JG, Plein M, Morgan ER, Vesk PA. Uncertain links in host-parasite networks: lessons for parasite transmission in a multi-host system. Philos Trans R Soc Lond B Biol Sci. 2017;372:20160095.

41. Epe C, Coati N, Schnieder T. Results of parasitological examinations of faecal samples from horses, ruminants, pigs, dogs, cats, hedgehogs and rabbits between 1998 and 2002. Dtsch Tierarztl Wochenschr. 2004:111:243-7.

42. Apt W, Aguilera X, Vega F, Alcaíno H, Zulantay I, Apt P, et al. Prevalence of fascioliasis in humans, horses, pigs, and wild rabbits in 3 Chilean provinces. Bol Oficina Sanit Panam. 1993;115:405-14.

43. Quigley A, Sekiya M, Egan S, Wolfe A, Negredo C, Mulcahy G. Prevalence of liver fluke infection in Irish horses and assessment of a serological test for diagnosis of equine fasciolosis. Equine Vet J. 2017;49:183-8.

44. Sekiya M, Quigley A, Garcia-Campos A, Mulcahy G. Experimental infection of Irish horses with Fasciola hepatica: O liver fluke, where art thou? 26th Int Conf World Assoc Adv Vet Parasitol. Malaysia: Kuala Lumpur; 2017. p. 574.

45. Nansen P, Andersen S, Hesselholt M. Experimental infection of the horse with Fasciola hepatica. Exp Parasitol. 1975;37:15-9.

46. Fairweather I, Boray JC. Fasciolicides: efficacy, actions, resistance and its management. Vet J. 1999;158:81-112.

47. Hanna REB, McMahon C, Ellison S, Edgar HW, Kajugu P-E, Gordon A, et al. Fasciola hepatica: a comparative survey of adult fluke resistance to triclabendazole, nitroxynil and closantel on selected upland and lowland sheep farms in Northern Ireland using faecal egg counting, coproantigen ELISA testing and fluke histology. Vet Parasitol. 2015;207:34-43.

48. Mooney L, Good B, Hanrahan JP, Mulcahy G, de Waal T. The comparative efficacy of four anthelmintics against a natural acquired Fasciola hepatica infection in hill sheep flock in the west of Ireland. Vet Parasitol. 2009;164:201-5.

49. Solana MV, Sierra R, Scarcella S, Neira G, Solana HD. In vivo assessment of closantel ovicidal activity in Fasciola hepatica eggs. Exp Parasitol. 2016;160:49-53. 
50. Sayers G, Good B, Hanrahan JP, Ryan M, Angles JM, Sweeney T. Major histocompatibility complex DRB1 gene: its role in nematode resistance in Suffolk and Texel sheep breeds. Parasitology. 2005;131:403-9.

51. Good B, Hanrahan JP, Crowley BA, Mulcahy G. Texel sheep are more resistant to natural nematode challenge than Suffolk sheep based on faecal egg count and nematode burden. Vet Parasitol. 2006;136:317-27.

52. Amarante AFT, Bricarello PA, Rocha RA, Gennari SM. Resistance of Santa Ines, Suffolk and lle de France sheep to naturally acquired gastrointestinal nematode infections. Vet Parasitol. 2004;120:91-106.

53. Buxton D, Maley SW, Wright SE, Rodger S, Bartley P, Innes EA. Toxoplasma gondii and ovine toxoplasmosis: new aspects of an old story. Vet Parasitol. 2007;149:25-8
54. Mason S, Quinnell RJ, Smith JE. Detection of Toxoplasma gondii in lambs via PCR screening and serological follow-up. Vet Parasitol. 2010;169:258-63.

\section{Publisher's Note}

Springer Nature remains neutral with regard to jurisdictional claims in published maps and institutional affiliations.
Ready to submit your research? Choose BMC and benefit from:

- fast, convenient online submission

- thorough peer review by experienced researchers in your field

- rapid publication on acceptance

- support for research data, including large and complex data types

- gold Open Access which fosters wider collaboration and increased citations

- maximum visibility for your research: over $100 \mathrm{M}$ website views per year

At BMC, research is always in progress.

Learn more biomedcentral.com/submissions 